\title{
Paula Alonso y Beatriz Bragoni (Editoras), El sistema federal argentino. Debates y coyunturas (1860-1910). Ciudad Autónoma de Buenos Aires: Edhasa, 2015, $304 \mathrm{pp}$.
}

Dapelo, Luciano Nicola

Centro de Investigaciones Históricas / Universidad Nacional de Río Cuarto - CONICET, Argentina

Inicoladapelo@gmail.com

Cita sugerida: Dapelo, L. N.(2018). [Revisión del libro El sistema federal argentino. Debates y coyunturas (1860-1910) por P. Alonso y Beatriz Bragoni (Ed.) ] Anuario del Instituto de Historia Argentina, 18 (1), e070. https://doi.org/10.24215/2314-257Xe070 


\title{
Paula Alonso y Beatriz Bragoni (Editoras), El sistema federal argentino. Debates y coyunturas (1860-1910). Ciudad Autónoma de Buenos Aires: Edhasa, 2015, 304 pp.
}

\author{
Luciano Nicola Dapelo \\ Centro de Investigaciones Históricas / Universidad \\ Nacional de Río Cuarto - CONICET, Argentina \\ lnicoladapelo@gmail.com
}

Esta obra ofrece una mirada renovada hacia un tema poco visitado para la segunda mitad del siglo XIX: el sistema federal en Argentina. Pese a ser un tópico por demás utilizado, son pocos los trabajos que se han dedicado a analizarlo en profundidad y este libro asume esa dirección complejizando los esquemas convencionales que le daban al poder coercitivo estatal y la cooptación de las élites locales un lugar unívoco en el proceso de consolidación del Estado Nacional. Inversamente, El sistema federal... invita a observar el proceso de centralización desde los debates en torno a la organización federal de la República, pero también, e invirtiendo el foco, nos introduce en las dinámicas provinciales y sus prácticas de relacionamiento con el gobierno central.

En el primer capítulo, Roberto Cortés Conde nos introduce en los orígenes del debate entre centralismo y descentralización poniendo foco en los aspectos fiscales. El autor inicia su análisis concentrándose en las rentas mineras potosinas que financiaban a las regiones internas más empobrecidas en el marco de la fuerte centralización que caracterizó la administración imperial borbónica, lo que habría sido origen de dos tendencias, una centralista, anudando a las ciudades de más antiguo poblamiento correspondientes al actual norte argentino, y una localista, que agrupaba a las más tempranas ubicadas en el litoral y caracterizadas como ciudades-puerto. Con la ruptura revolucionaria, la pérdida del Alto Perú y el paso a una economía de base ganadera durante las autonomías provinciales, la renta, y por tanto el federalismo en el análisis de Cortés Conde, se concentró en el cobro de aduanas internas, aunque el monopolio del puerto por parte de Buenos Aires, explicaría la presión ejercida por las demás provincias para reintegrarla luego de la secesión de 1852. Esta situación explicita el fracaso del "pacto fiscal federal" establecido por la Constitución de 1853, puesto que al eliminar las aduanas internas les quitaba a las provincias su mayor ingreso, al tiempo que la "hermana mayor" renegaba de entregar su aduana al resto del territorio.

En 1859, luego de siete años de separación, Buenos Aires inicia el proceso para reincorporarse a la Confederación, aunque imponiendo condiciones que se plasmaron en la reforma de la Constitución provincial. Los debates que rodearon esa reforma son analizados por Leo y Gallo enfocándose en dos cuestiones sensibles para los intereses de ambos Estados: la renta aduanera y la cuestión de la capital. Más allá de las consideraciones acerca de si las primeras corresponderían a la Nación o a las provincias y si, respecto al segundo punto, debía ser Buenos Aires o algún otro lugar del territorio ahora unificado, el análisis de los autores se concentra en las disputas entre la facción aislacionista, liderada por Valentín Alsina y la de los partidarios de una organización federal encabezada por Buenos Aires, unida en torno a Bartolomé Mitre. En ese análisis, el esfuerzo de guerra en el conflicto de la Triple Alianza que llevó a la centralización de la aduana y la indefinición de la cuestión capital, mostraron el fracaso de la tendencia federal en ambos aspectos, pese a la existencia firme de la posición que esgrimía que los derechos de exportación correspondían a las provincias.

Si la cuestión federal se frustró en esos puntos, en la práctica política podemos encontrar matices. Concentrándose en el proceso eleccionario presidencial de 1868, Eduardo Míguez, en el capítulo 3, señala la relevancia de esa elección que trae aparejada la novedad de constituirse en la primera prueba electoral en 
la que los aparatos políticos "nacionales" deben recurrir a la negociación con los gobiernos provinciales. En ese sentido, el triunfo de Sarmiento por sobre el mitrismo, muestra el peso cada vez más relativo de las élites del interior menos dispuestas a aceptar sin condicionamientos la hegemonía de los porteños. El estudio de Míguez aporta además una clasificación interesante entre un federalismo "reaccionario" o pragmático, propio de la Confederación Rosista, con sus últimos estertores en las montoneras de la década de 1860, frente a otro de carácter "reformista" enarbolado por Urquiza e impulsado por Mitre orientado a la organización estatal con base en el sistema federal; federalismo reformista del cual, en virtud de los resultados de 1868, el propio Mitre fue víctima.

Los textos de Beatriz Bragoni (capítulo 4) y María Celia Bravo (capítulo 5) pueden merecer una lectura conjunta, pues ambos, concentrados en los años que median entre 1870 y 1890 nos muestran la capacidad del Estado central como regulador y "estabilizador" de las situaciones provinciales, pero al mismo tiempo advierten que dicha capacidad responde, no a la autoridad compacta e incuestionable de ese Estado, sino la permeabilidad de los grupos dirigentes locales ante ese poder en tanto sirviera para mantenerse en el gobierno y asegurar el "progreso material" provincial o más bien, de sus élites gobernantes. La primera autora, concentrándose en la provincia de Mendoza, desanuda los avatares de la política local en la confrontación alterna entre los dos grupos de mayor preeminencia: "gonzalistas" y "civitistas". En ese análisis las banderas del federalismo, la autonomía y la libertad fueron enarboladas por uno y otro grupo en conexión con la política nacional en tanto ésta se convierte desde mediados de la década de 1870 en la instancia de mediación que impulsa salidas transaccionales a los conflictos locales o cuenta, como en 1889, con el recurso de la intervención federal. Con ello, Bragoni demuestra con habilidad como la centralización del roquismo así como la descentralización del juarismo son herramientas analíticas eficaces que permiten observar la dinámica de "ida y vuelta" entre un Estado que interviene y una dirigencia provincial que utiliza su influencia.

Bravo, por su parte, analiza la provincia de Tucumán y divide el arco temporal que aborda en tres momentos según el significado que las dirigencias dan al federalismo como práctica. En ese esquema encuentra que entre 1870 y 1880 las dirigencias provinciales se vuelcan hacia el federalismo alberdiano queen el caso particular implica un apoyo al centralismo estatal, principalmente en la lógica del presidente Sarmiento que pretendía desarticular a los Taboada que, desde Santiago del Estero, dominaban a las provincias del norte; en ese caso, entonces, la vocación federal-centralista de la dirigencia tucumana implicaba la defensa de la autonomía en oposición al control por parte de la provincia vecina. A partir de $1880 \mathrm{y}$ hasta 1887 la autora indica la existencia de un federalismo cooperativo: la necesidad de infraestructura, créditos y políticas impositivas para la creciente industria azucarera en la provincia hizo preciso adecuar el discurso federal a fin de asegurar el "progreso material” de Tucumán. Esta solidaridad se quiebra en 1887 cuando la intervención federal de la mano de los juaristas provinciales desde las agencias del Estado Nacional, acabaron con la administración provincial que se había volcado por la ya frustrada candidatura de Bernardo de Irigoyen, inaugurando el período del federalismo defensivo, que esta vez se guía por el vértice político, contra la injerencia y/o prescindencia del gobierno nacional en la política local.

Seguidamente, Gustavo Paz se introduce en las dinámicas políticas jujeñas en torno a 1880. El eje de su observación es demostrar la creciente injerencia de autoridades nacionales, como la Suprema Corte de Justicia de la Nación, el Ejército Nacional y los recursos financieros del gobierno central en la política provincial pero, como en los casos de Tucumán y de Mendoza, no por su fuerza impersonal y omnipotente, sino atraídas por las facciones locales con el objeto de inclinar la balanza a favor propio. Ello se complementa con el examen de la crónica histórica del jurista jujeño Joaquín Carrillo, en la que el autor intenta demostrar que la provincia norteña fue, desde 1811, el baluarte de la construcción de la Nación y su prédica por un "federalismo solidario" que, lejos del pernicioso localismo, sirva como una recompensa a los sacrificios de Jujuy a través de una distribución más amplia de los beneficios de lo que Carrillo juzga como, progresos de su presente.

En tónica con lo anterior, pero con foco en Córdoba y a partir de dos momentos de intervención del fuero federal, Laura Cucchi se concentra en el accionar de la Justicia Federal que representaba la mayor autoridad 
federal permanente en las provincias. En este capítulo se pone en evidencia la conflictividad respecto de la jurisdicción de aplicación de las penas, si la nacional o la provincial, en pleno conflicto entre nacionalistas, que dominaban las primeras y autonomistas, que hacían lo propio con las segundas, en el marco general de la fracasada política de conciliación de partidos iniciada por el presidente Nicolás Avellaneda. A partir de las observaciones de la autora se pone de manifiesto que la Justicia Federal era un instrumento eficaz para moderar conflictos y controlar el ejercicio de poder de los gobernadores, limitando su capacidad de acción en la arena electoral y militar.

Paula Alonso, por su parte, tomando como ejes la hibridez del PAN como coalición gobernante que favorece la descentralización federal, el contraste entre el liderazgo centralista de Roca y el laissez faire de Juárez Celman, las diferencias entre el pujante litoral pampeano y el resto del interior con economías menos desarrolladas particularmente ante el desafío modernista de 1890, las coyunturas económicas de expansión o contracción que dan mayor o menor ímpetu al centralismo económico y los debates en torno al federalismo, concentrados en las prácticas políticas en mayor o menor medida violatorias del espíritu federal de la Constitución Nacional, demuestra eficazmente las dinámicas del federalismo en las últimas dos décadas del siglo XIX

Finalmente, Roldan, en el noveno capítulo, analiza la propuesta de reforma de dos intelectuales en torno al centenario de la Revolución de Mayo y las concepciones y genealogías que establecen respecto de la génesis, carácter y "falseamiento" del sistema federal. En ello, la propuesta de Rodolfo Rivarola de suprimir el régimen federal y reemplazarlo por el unitarismo centralista de base municipal, contrasta con la visión más moderada de José N. Matienzo que aboga por un federalismo reformado que asegure una vigencia "real" del federalismo y no "artificial" como juzgaba que existía en el momento, pero ambos revelan la vigencia del debate acerca de la cuestión federal y sus opacidades en tres formas: en el lenguaje republicano, en la introducida por la desnaturalización de las instituciones y en la de las instituciones respecto del gobierno representativo.

En síntesis, podemos hallar al menos tres líneas que guían los nueve trabajos aquí reunidos. Por un lado, con fuerte apoyatura empírica, los trabajos de Míguez, Bragoni, Paz y Cucchi nos brindan de una parte, un panorama exhaustivo de las injerencias del Estado Central en diferentes provincias del interior argentino y la permeabilidad o no de sus élites a los influjos de ese proceso, advirtiendo de qué manera los grupos de poder locales utilizan en sus prácticas políticas los márgenes de acción que les permiten las instituciones estatales; de otra, este conjunto de producciones evidencian la complejidad del proceso de construcción de un federalismo centralista que, en todos los casos, precisó "negociar” con la política local para poder imponerse.

En una segunda línea podemos ubicar los capítulos de Leo y Gallo y el de Roldán. En los dos casos, el análisis está centrado en los debates en torno a la concepción del federalismo por parte de los contemporáneos a los procesos que analizan. En este agrupamiento, por último, cabe señalar una tercera línea compuesta por los trabajos de Cortés Conde, Bravo y Alonso, que ofrecen una mirada más bien "panorámica" respecto del tópico central que reúne a los autores. En un caso desde los aspectos fiscales y económicos, en otro, incorporando el análisis del esquema institucional y las vicisitudes políticas y en un tercero, tomando la provincia de Tucumán como testigo, se ofrece una mirada más procesual acerca de la génesis, significado, alcances y limitaciones del federalismo en la tensión dicotómica entre centralización y descentralización.

En suma, a partir de las diversas contribuciones, se elucidan los aspectos colaborativos del federalismo advirtiendo que en el proceso de construcción de un Estado central Federal, el gobierno nacional comparte su protagonismo con los provinciales. Como Natalio Botana lo señala en su epílogo, los debates acerca del carácter teórico y práctico del federalismo en la República Argentina han recobrado un renovado interés en los primeros años del siglo XXI, por lo que esta obra adquiere una especial vigencia y peso específico propio; entonces, El sistema federal... se constituye en una obra de suma relevancia en tanto nos indica que el federalismo centralista de la segunda mitad del siglo XIX ofreció a las provincias procesos de desarrollo económico y demográfico inéditos y le dio a sus dirigencias un protagonismo político central. 